\title{
ECMO in India, SWAAC ELSO: challenges and solutions
}

\author{
Suneel Kumar Pooboni ${ }^{1}$ (D)
}

Received: 23 January 2020 / Revised: 29 July 2020 / Accepted: 31 July 2020 / Published online: 9 September 2020

(C) Indian Association of Cardiovascular-Thoracic Surgeons 2020

\begin{abstract}
The innovations leading to the development of a new technology such as extracorporeal membrane oxygenation (ECMO) and its progress over the years have been inspiring. Many great personalities were associated with the genesis and re-designing the multiple essential components of ECMO to make it more biocompatible. We discussed the brief history of cardiopulmonary bypass and ECMO. We elucidated the establishment of a commanding center, Extracorporeal Life Support Organization (ELSO) in the USA, ECMO society of India in the sub-continent and the birth of South and West Asia Chapter (SWAC) of ELSO initially, which became South and West Asia, Africa chapter (SWAAC) ELSO later after amalgamation of Africa to this sub-chapter of ELSO.
\end{abstract}

Keywords ECMO $\cdot$ Cardiopulmonary bypass $\cdot$ ELSO $\cdot$ SWAC ELSO $\cdot$ SWAAC ELSO

\section{Introduction}

History of development of cardiopulmonary bypass technology and extracorporeal membrane oxygenation (ECMO) help us understand the changes in medical science over the last century. Based on the principles of cardiopulmonary bypass, with the added advantage of addition of heparin to aid in anticoagulation, helped the science of ECMO to move towards wider applicability. Further developments in improving the designs of the essential components of ECMO (membrane oxygenators, pumps, biocompatibility issues, miniaturization) over the years helped in wider acceptance besides making the practice of ECMO safe. We described the evolution of the ECMO practices and the organizations safe-guarding the practice of ECMO over the globe.

Extracorporeal Life Support Organization (ELSO) was established in 1989 at Ann Arbor, MI, USA. Description of ELSO is not complete without mentioning the history of ECMO.

The science of ECMO developed over the past 7 decades. The origins of cardiothoracic surgery and ECMO share their roots together.

The thoughts about invention of a mechanical circulatory support system have developed over the years. Many researchers put their efforts together in building this life support

Suneel Kumar Pooboni poobonisk@gmail.com

1 Mediclinic City Hospital, Dubai, Abu Dhabi, United Arab Emirates system. Dr. John Gibbon was one such inspiring personality [1]. He was a research fellow at Harvard Medical School, USA in 1931. The surgical team under Dr. Churchill performed pulmonary embolectomy on a patient after she developed massive pulmonary embolism [2]. As a fellow, Dr. Gibbon looked after the patient during her hospital stay. Unfortunately, she passed away. In an effort to find a solution to similar problems, Dr. Gibbon struggled to develop a mechanical device which could look after the function of lungs until the patient recovers. In 1953, following his work along with his wife Mary Gibbon, he performed the first successful open-heart surgery on an atrial septal defect (ASD) patient [3]. This was the first cardiopulmonary bypass procedure in history. As the subsequent patients died, Dr. Gibbon was disappointed with his machine. Later, together with Mayo collaboration, they made the Mayo-Gibbon heart-lung machine, leading to many more success stories. Further developments were added by enthusiastic physicians such as John Kirklin at the Mayo Clinic and C. Walton Lillehei at the University of Minnesota and Dr. Theodor Kolobow at the National Health, Lung, and Blood Institute at the NIH, Bethesda, Maryland, just to name a few. As a result of the contributions of many more dedicated researchers and clinicians, the safety standards of today in the practice of ECMO could be seen as a reality. They contributed to further advances in design, development of biocompatible membrane oxygenators, circuit, etc.

In 1971, Dr. Donald Hill, a cardiac surgeon, used ECMO for saving an adult following road trauma with aortic rupture. Further success in adult patients could not be claimed for the 
next few years. In 1975, Dr. Robert Bartlett successfully used ECMO in a newborn following meconium aspiration syndrome to treat lung failure. This was the baby of a poor immigrant mother from Mexico. The baby was named Esperanza by the nurses, meaning "Hope" in Spanish. Her success story was the initiation of ECMO in the neonatal population. Treating further patients on ECMO over the next couple of decades resulted in variable outcomes. Dr. Robert Bartlett trusted the principle of ECMO and continued it as a therapeutic modality. Further randomized controlled trials in the UK and USA established the role of ECMO in cases of reversible lung or cardiopulmonary failure as a support mechanism for varying periods of time.

\section{Birth of ELSO}

With the noble idea of establishing an organization to share the knowledge and developments in the field of ECMO, Dr. Robert Bartlett and his associates established ELSO [4]. The first conference was held in Ann Arbor, MI, USA, in 1989. The Extracorporeal Life Support Organization (ELSO) is a nonprofit organization consisting of professionals and scientists who are involved in doing and researching ECMO. Physicians and surgeons from many interested centers in the USA and Europe came together under one umbrella. ELSO maintains a registry of both facilities and specialists trained to provide ECMO services [5]. ELSO also maintains registry information of different clinical conditions treated on ECMO in great detail and helps in analysis of these results in an anonymous way to maintain the confidentiality of different centers. Table 1 shows the International registry data including the number of cases done in neonatal, pediatric, and adult populations. It also depicts the growth of ELSO-registered centers worldwide. The ELSO registry data will be of great help for other clinicians to understand if they contemplate putting a patient with similar condition on ECMO. The data is used to support clinical research, regulatory agencies, and individual ELSO centers. ELSO provides educational programs for active centers as well as for facilities who may be involved in the transfer of patients to higher levels of care [6]. There are different sub-committees such as Registry development committee, Scientific oversight committee, and Registry quality committee. ELSO website provides resources for prospective centers in the form of policies and procedures and guidelines. ELSO publishes the ECMO manual and the text book, traditionally called the Redbook.

The advantages of having a worldwide organization and the unique aspects of a scientific group with representation from all healthcare professional participants in the activities of the organization are very useful for the growth and standardization of ECMO practices. Mr Peter Rycus has been the executive administrator of ELSO. ELSO also provides small research grants which can be used to facilitate registry projects.
ELSO has been useful to ECMO centers and practitioners worldwide in several ways. The worldwide registry is available for quick reference, documentation, publication, and quality assurance for member centers. ELSO has served as the communications center for ECMO-related information.

Until 2012, there was only central (American) ELSO. The organization has realized the need for covering the rest of the parts of the world besides the USA, which subsequently lead to the creation of sub-chapters., viz., Euro ELSO, Asia Pacific ELSO, Latin American chapter of ELSO, and South and West Asia, Africa chapter of ELSO.

\section{ECMO Society of India and birth of SWAC ELSO}

South and West Asia chapter of ELSO (SWAC ELSO) [7] was established in the year 2013 as a result of combined efforts of the members of ECMO Society of India and Extracorporeal Life Support Organization, ELSO. ECMO Society of India (ESOI) was established in 2010 with the ideals of improving awareness and practice of ECMO in India. It was initiated by two enthusiastic ECMO practitioners, Dr. Pranay Oza and Dr. Venkat Goyal along with interested clinicians from all over the country. The platform was used for improving knowledge about the practice of ECMO, arranging training programs and annual conferences within India. The program was supported by international faculty who have been actively doing and teaching ECMO. Between 2012 and 2013, the clinicians of ECMO society of India were engaged with ELSO Steering Committee members, who aptly proposed the expansion of ELSO to cover South East Asia and West Asia part of the globe. On June 2013, at the 4th ECMO Society conference held at New Delhi, India, the South \& West Asia ELSO chapter was established with me as the founder chairman. Member representatives from the participating countries were selected to represent and lead the ECMO activities in their respective countries [7]. At the time the chapter was founded, there were countries which have been actively doing ECMO besides those who wanted to introduce ECMO as an expansion to their existing critical care/cardiothoracic surgical activities. SWAC ELSO stood as a uniting platform sharing the values of ELSO despite the regional and economic differences, representing unity in diversity. The main intention has been to support and improve understanding and practice of extracorporeal life support systems in the member countries. The first annual conference of SWAC ELSO was held at Hyderabad, India, from 31 Jan to 1 Feb 2014. There was enthusiastic participation from member countries with collaboration to learn from each other's experience. Figures 1 and 2 are showing the attendees and faculty at the first and second conferences of SWAC ELSO.

SWAC ELSO region in 2013 was representative of the following member countries: 
Table 1 International Report January 2020

\section{ECLS Registry Report}

International Summary

January, 2020

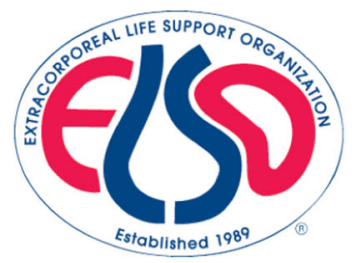

Extracorporeal Life Support Organization 2800 Plymouth Road

Building 300, Room 303 Ann Arbor, Ml 48109

\section{Overall Outcomes}

Total Runs

Total

\section{Total Runs}

\begin{tabular}{lrrrrr}
\hline Neonatal & & & & & \\
Pulmonary & 32,385 & 28,417 & $87 \%$ & 23,675 & $73 \%$ \\
Cardiac & 8,830 & 6,097 & $69 \%$ & 3,818 & $43 \%$ \\
ECPR & 2,035 & 1,427 & $70 \%$ & 861 & $42 \%$ \\
Pediatric & & & & & \\
Pulmonary & 10,346 & 7,471 & $72 \%$ & 6,199 & $59 \%$ \\
Cardiac & 12,538 & 9,042 & $72 \%$ & 6,667 & $53 \%$ \\
ECPR & 4,945 & 2,940 & $59 \%$ & 2,086 & $42 \%$ \\
Adult & & & & & $60 \%$ \\
Pulmonary & 24,395 & 16,971 & $69 \%$ & 14,714 & $43 \%$ \\
Cardiac & 25,488 & 15,184 & $59 \%$ & 11,191 & $29 \%$ \\
ECPR & 8,075 & 3,363 & $41 \%$ & 2,387 & \\
Total & 129,037 & 90,912 & $70 \%$ & 71,598 & $55 \%$ \\
\hline
\end{tabular}

Survived to DC or Transfer

\section{Centers by year}


South Asia: Bangladesh, Bhutan, India, the Maldives, Nepal, Pakistan, Sri Lanka, and Afghanistan.

West Asia: Armenia, Azerbaijan, Bahrain, Egypt, Georgia, Iran, Iraq, Israel, Jordan, Kuwait, Lebanon, Oman, Palestine, Qatar, Saudi Arabia, Syria, Turkey, United Arab Emirates, and Yemen.

In 2015, Africa was added to the SWAC region making it SWAAC (South and West Asia, Africa chapter of ELSO). The incorporation of African region increased the number of participating countries to 83. Figure 3 is showing ELSO-registered centers worldwide. Table 2 is showing SWAAC ELSO-registered ECMO centers.

The initial logo of SWAC ELSO in 2014 is shown in the figure below:

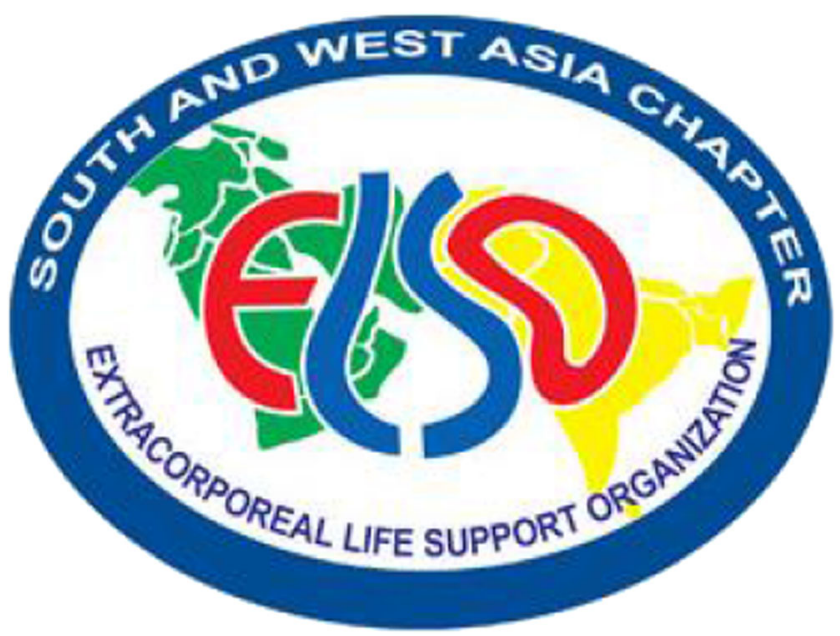

The subsequent logo of SWAAC ELSO in 2015 after addition of Africa is shown below, representing South Asia, West Asia, and Africa:

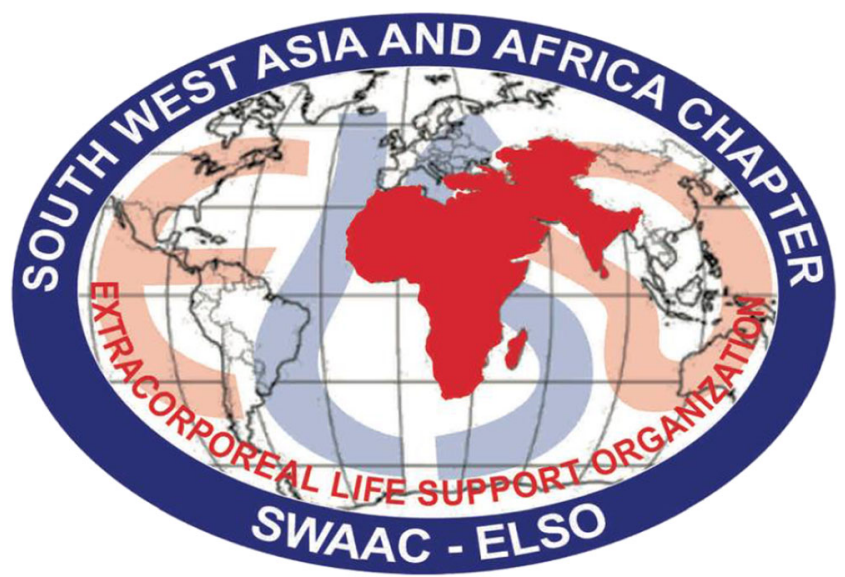

Infection has been playing a significant role in deciding mortality on ECMO. Bizzaro et al. reported infection rates being highest in the adult vs. the pediatric and neonatal populations (30.6 vs. 20.8 vs. 10.1 infections per $1000 \mathrm{ECMO}$ days, respectively) and in those requiring extracorporeal cardiopulmonary resuscitation (ECPR) (24.7 infections per 1000 ECMO days) [8]. Prevalence of infection increased with prolonged duration of ECMO duration of ECMO. As the multidrug resistance (MDR) is reported to be high with the local flora, it will be worth looking for strict implementation of safe infection control precautions and antibiotic stewardship programs to keep the emergence of MDR strains low.

South Asia, West Asia, and Africa are special with respect to the challenges offered to the healthcare delivery [9]. The indications for ECMO have been varying in this geographic region. Myocarditis due to scorpion stings, snake bites, supporting patients post poisoning like organo-phosphorous poisoning, and exposure to various other poisons such as celphos poisoning are some of the examples. Acute respiratory distress syndrome (ARDS) secondary to malaria, tuberculosis, typhus, dengue, and other newer varieties of viral pneumonias (SARS, H1NI, MERS, H5N1, H7N9, etc.) offer exciting opportunities for application of this life-saving modality. Controlling drug-resistant infections is a priority for the successful run of ECMO. Other challenges also exist like the lack of ideal transport facilities in most of the countries. Cardiac ECMO as extended cardiopulmonary bypass is practiced much more widely than respiratory ECMO. These are huge challenges, yet interesting avenues to discover innovative methodology resulting in improvements in healthcare throughout the world.

ECMO is one of the high-cost therapies as much of the disposable equipment has to be imported. With innovations in healthcare and manufacturing cannulae, circuits, and oxygenators locally, it is possible to bring down the cost of ECMO therapy. For entrepreneurs to invest in the manufacturing sector, they should be assured of a high volume of cases. Once the number of ECMO centers increases and SWAAC countries come together with mutual co-operation, it is possible to offer ECMO for reasonable cost. SWAAC ELSO consists of centers which provide ECMO as part of National Health service as well as those in developing countries offering ECMO on selffunding. Meanwhile, exploring several paths for procuring finances such as effective utilization of the available funds, healthcare insurance schemes made affordable to majority of population by increasing awareness, private healthcare schemes provided by the corporate sector, crowdfunding, healthcare charities, and to some extent, personal funding should help in making the life-saving healthcare options such as ECMO affordable to upper and middle income group families. It would be worthwhile for government-funded/autonomous apical institutions to adopt this technology in a cost-effective way as they have the resources and man power available freely. 


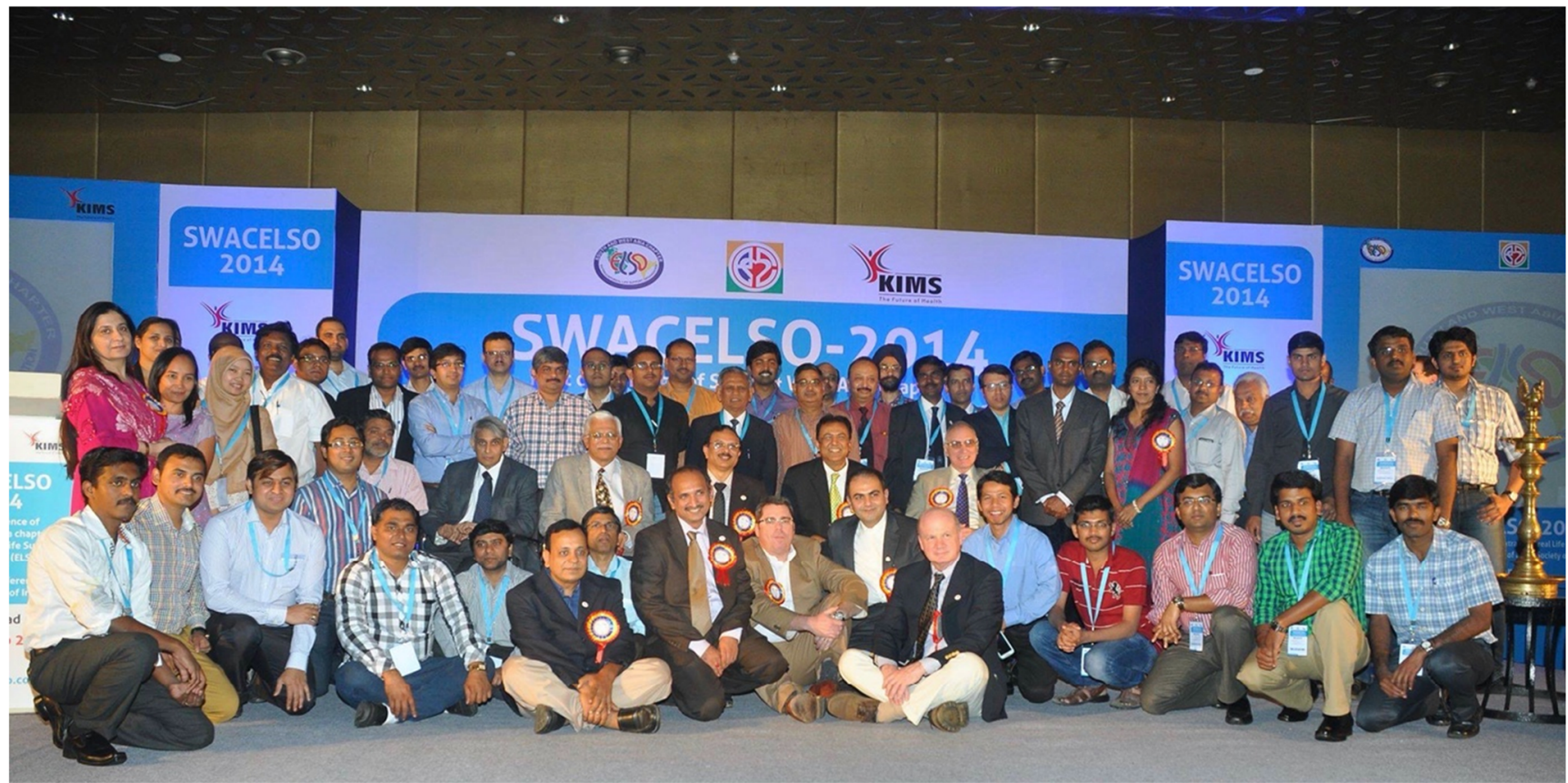

Fig. 1 First annual conference of SWAC ELSO 2014

COVID-19 is posing significant problems to healthcare infrastructure in the entire world. ELSO community unanimously agreed that in a pandemic, healthcare resources should be targeted for proving the essential basic healthcare for the affected people [10]. ECMO, as a resource intensive therapy, should be applied in carefully selected patients with the greatest chance of benefit from receiving ECMO in centers with sufficient expertise and capacity to do so safely. We are still learning the different ways in which this disease affects humans. Until 3 June 2020, out of 131 patients placed on ECMO in the SWAAC region, 53 survived (personal communication Dr. Ahmed Rabie). SWAAC ELSO member countries played their role in extending ECMO support to the needy at the right point of time along with the sister chapters of ELSO.

Lastly, becoming an ELSO member would be useful for the ECMO practitioner and the institution to self-regulate themselves and keep the standards upheld. By analyzing our own data in a confidential manner and comparing it with the international scenario will help in acknowledging our merits and demerits, thereby helping the institutions to audit their performance. It also helps in updating our knowledge, promotional offers to uplift our units and compete for the best ECMO center of excellence awards. The fees for corporate ELSO membership are also reasonably priced according to the world bank rankings of economies of the countries. Table 3 is showing SWAC ELSO-registered Indian centers

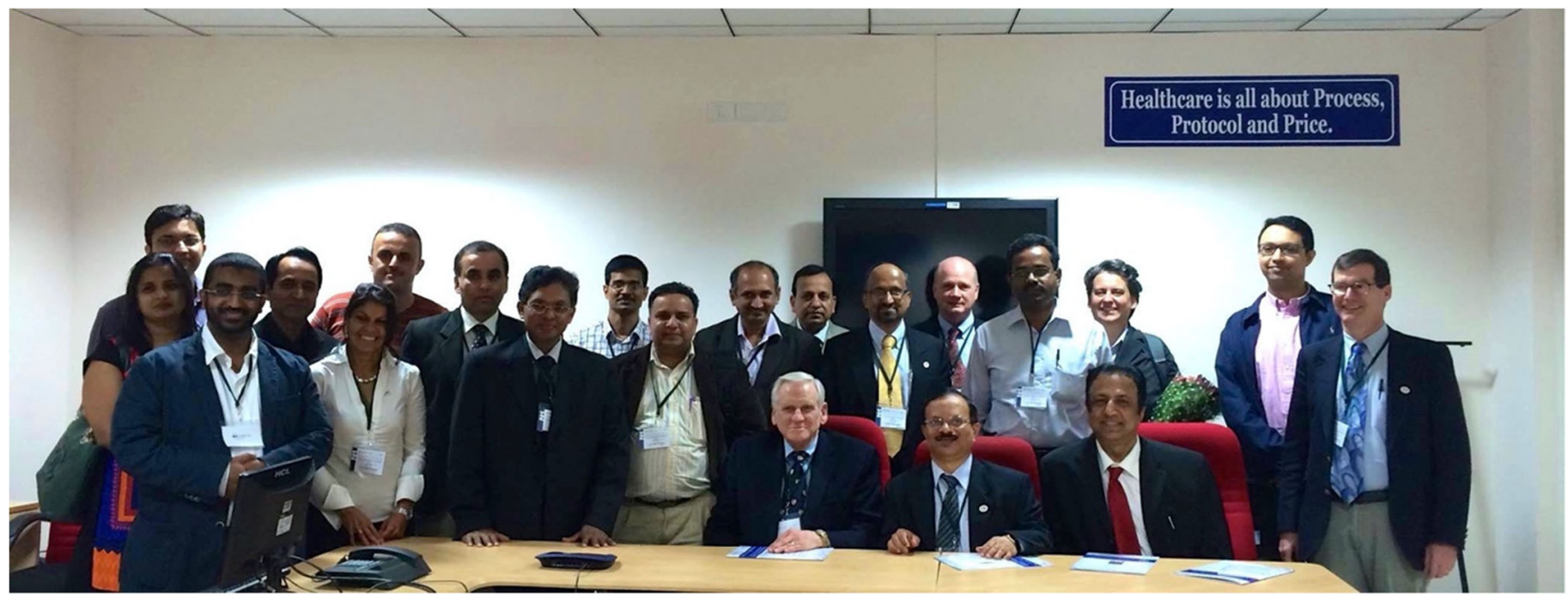

Fig. 2 Second annual conference of SWAC chapter of ELSO 2015 Bengaluru, India 


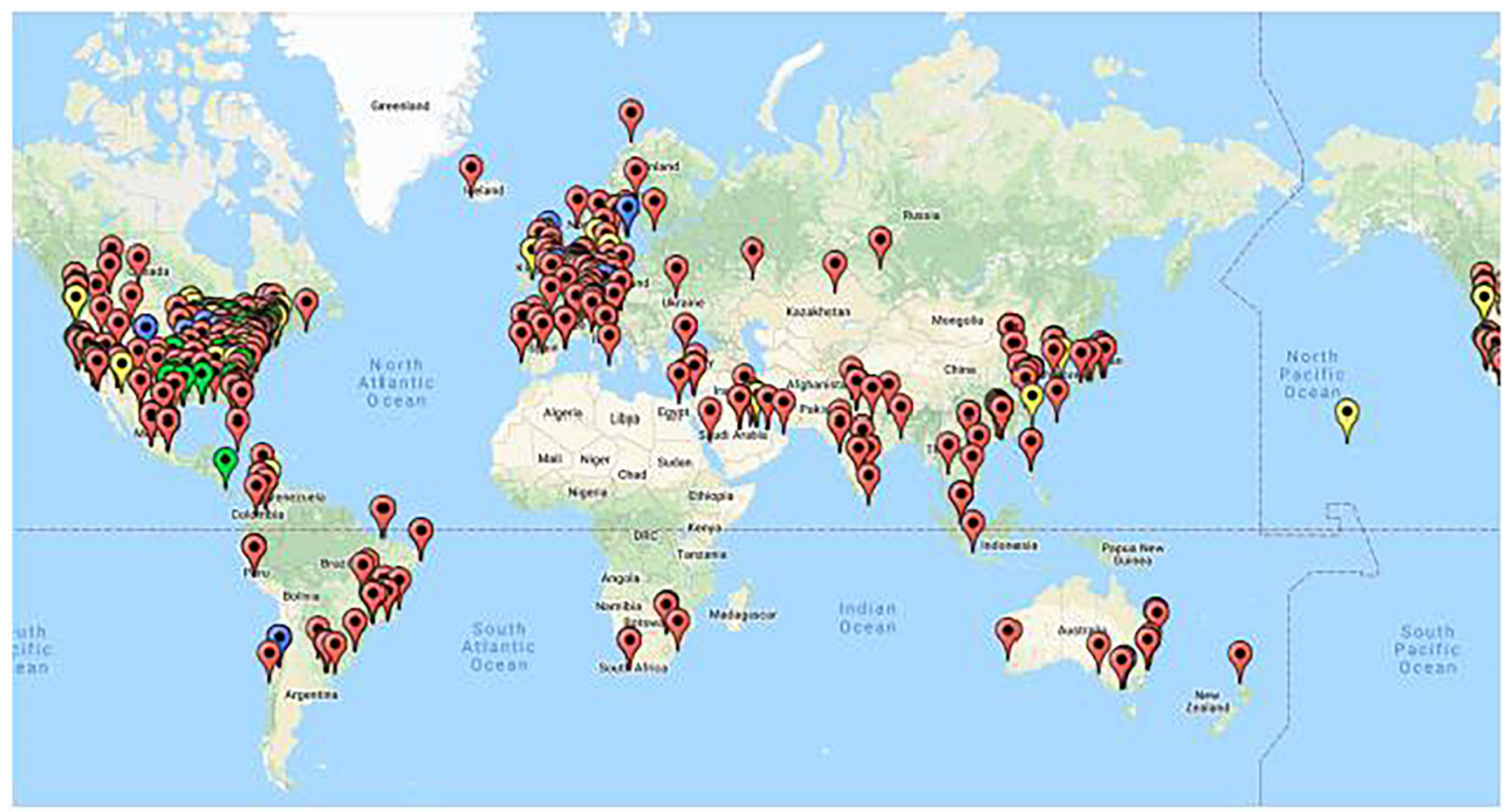

Fig. 3 ELSO centers worldwide (reproduced with permission of Peter Rycus, ELSO)

Table 2 SWAAC chapter of ELSO countries
South and West Asia, Africa chapter of ELSO

\begin{tabular}{ll}
\hline Bahrain & \\
Egypt & \\
India & Bangalore \\
& $\begin{array}{l}\text { Gurgaon } \\
\text { Ludhiana } \\
\text { Mumbai }\end{array}$ \\
& New Delhi \\
& Secunderabad \\
& Surat \\
& Chennai \\
& Bengaluru \\
& Hyderabad \\
& Lucknow \\
& Kolkata \\
& \\
Kazakhstan & \\
Kuwait & \\
Lebanon & \\
Nepal & \\
Qatar & \\
Saudi Arabia & \\
South Africa & \\
Sri Lanka & \\
\hline
\end{tabular}

Table 3 SWAC ELSO-registered Indian centers as on July 2020

\begin{tabular}{|c|c|c|}
\hline Country & City & ECMO center \\
\hline \multirow[t]{20}{*}{ India } & Bangalore & Fortis hospital \\
\hline & Bangalore & Aster CMI Hospital \\
\hline & Bangalore & Manipal hospital, whitefield \\
\hline & Bangalore & Narayana Institute of Cardiac Sciences \\
\hline & Gurgaon & Fortis Memorial Research Institute \\
\hline & Ludhiana & Dayanand Medical College \\
\hline & Mumbai & Kokilaben Dhirubhai Ambani Hospital \\
\hline & Mumbai & $\begin{array}{l}\text { Riddhi Vinayak Critical Care and Cardiac } \\
\text { Centre }\end{array}$ \\
\hline & New Delhi & The Simulation Society (TSS) at AIIMS \\
\hline & New Delhi & Holy Family Hospital \\
\hline & $\begin{array}{l}\text { Hyderabad and } \\
\text { Secunderabad }\end{array}$ & Krishna Institute of Medical Sciences \\
\hline & Hyderabad & Rainbow Children's hospital \\
\hline & Hyderabad & Star hospitals \\
\hline & Hyderabad & Yashoda Hospitals \\
\hline & Hyderabad & AIG Hospitals \\
\hline & Surat & Unique Hospital \\
\hline & Chennai & Apollo Hospitals \\
\hline & Chennai & $\begin{array}{l}\text { Sri Ramachandra Medical Centre (Sri } \\
\text { Ramachandra Institute of Higher } \\
\text { Education and Research) }\end{array}$ \\
\hline & Lucknow & $\begin{array}{l}\text { Dr. Ram Manohar Lohia Institute of } \\
\text { Medical Sciences }\end{array}$ \\
\hline & Kolkata & Medica Superspecialty Hospital \\
\hline
\end{tabular}

(Reproduced with permission of Peter Rycus, ELSO) 
as on July 2020. We encourage individual ECMO centers to become ELSO members.

Acknowledgments My sincere thanks to Mr. Peter Rycus for giving permission to share ELSO data.

Funding No funding was received.

Data and/or code availability and author's contribution statements The paper is a brief description of history of cardiac surgery/ELSO and personal experiences. For information regarding ELSO, permission was taken from Mr. Peter Rycus, Executive administrator, ELSO and was acknowledged in the manuscript.

\section{Compliance with ethical standards}

Ethics approval Our paper does not need ethics approval as the subject is the history of two organizations.

Conflict of interest The author declares that he has no conflict of interest.

\section{References}

1. Henry Edmunds L. Advances in the heart-lung machine after John and Mary Gibbon. Ann Thorac Surg. 2003;76:S2220-3.
2. Cohn LH. Fifty years of open-heart surgery. Circulation. 2003;107: 2168-70. https://doi.org/10.1161/01.CIR.0000071746.50876.

3. Hill D. Dr H Gibbon Jr: Part 1. The development of the first successful heart-lung machine. Ann Thorac Surg. 1982;34:337-41 https:/www.annalsthoracicsurgery.org/article/S0003-4975(10) 62507-6/pdf. Accessed 15 March 2020.

4. Extracorporeal Life Support Organization - Wikipedia https://en. wikipedia.org > wiki > Extracorporeal_Life_Support_Organization. Accessed 17 Feb 2020

5. ELSO: https://www.elso.org/. Accessed 17 Feb 2020

6. Extracorporeal Life Support Organization - ECMO and ECLS > Excellence $>$ Vision. www.elso.org. Retrieved 2020-07-17.

7. Pooboni S. SWAC ELSO: past, present and future. Qatar Med J. 2017, 2017;9. https://doi.org/10.5339/qmj.2017.swacelso.9.

8. Bizzarro MJ, Conrad SA, Kaufman DA, Rycus P. Infections acquired during extracorporeal membrane oxygenation in neonates, children, and adults. Pediatr Crit Care Med. 2011;12:277-281.

9. Pooboni S. ECMO: An Indian perspective, challenges and opportunities. J Pediatr Crit Care. 2017;4:33-37.

10. Shekar K, Badulak J, Peek G, et al. 2019 Interim guidelines: a consensus document from an international group of interdisciplinary extracorporeal membrane oxygenation providers. ASAIO J. 2020;66:707-21. https://doi.org/10.1097/MAT. 0000000000001193 .

Publisher's note Springer Nature remains neutral with regard to jurisdictional claims in published maps and institutional affiliations. 